in the potentialities and limitations of the tools of their trades. This also applies to the excellent chapters on the benefits of treatment, and management of anaesthesia in the hypertensive patient. In fact, the first $75 \%$ of the book was a real pleasure to review, combining true educative value with the excitement of ongoing constructive research.

Unfortunately, the last part of the book on treatment with different groups of antihypertensive drugs was to prove a disappointment for in some chapters it lacks the clarity and critical approach which marked the earlier part. The information presented in these chapters often appears to be parochial or to have been obtained more from an uncritical and incomplete review of literature than from wide personal experience of the authors. This is, perhaps, best illustrated by the unqualified statement-'The rauwolfia alkaloids have been largely superseded by more effective and better tolerated hypotensive agents'. The young author is, presumably, unaware that Rauwolfia is still the most widely used antihypertensive agent in the world and is considered by many of our overseas colleagues to be both effective and well tolerated. Nevertheless, the book as a whole was well worth reading, and should provide something of exciting interest to clinicians in most specialities.

Malignancies of the Ovary, Uterus and Cervix. The Management of Malignant Disease Series No. 2 (Edited by M. J. Peckham and R. L. Carter)

By Raymond S. Bush Pp. viii +242, illustrated. Edward Arnold, London, 1979. £13.95.

This is the second in a series of books devoted to the management of malignant disease. It is commendable that such an important topic has been chosen as an early contribution to the series, for the recent advances in the management of gynaecological cancer need to be brought to the attention of postgraduates. The author with his wide experience, and the data of The Princess Margaret Hospital, is in a good position to give an authoritative view.

The main body of the book is devoted to carcinoma of the ovary, uterus and cervix; and the natural history, evaluation and management of these tumours are dealt with thoroughly. It is pleasing to see that sections are included on such topics as the quality of life, the value of screening and prognostic factors other than stage of the disease. The main purpose of this book is to deal with management and it is successful in doing this.

The inclusion of a chapter on end points for evaluating treatment is of course particularly relevant in the care of gynaecological malignancy. However, it is just as important in many other malignant diseases which will presumably be dealt with subsequently. This section and the section on Biological concepts underlying cancer treatment, by Richard Hall, should be brought together in a volume in the series. The editors could be in danger of making the individual volumes too diffuse if these worthwhile contributions are scattered among the series.

\section{National Food Policy in the UK. CAS Report 5.}

Centre for Agricultural Strategy. Pp. 116. Centre for Agricultural Strategy, University of Reading, 1979. £2.85. No national food policy exists in Britain. Although it is widely accepted that health is affected by the type and quantity of food eaten, health is excluded from consideration in policies that determine food supply. Recently, interest has been growing in Britain, as internationally, in the need for food and nutrition planning. This report reviews the present situation in Britain, and a wide variety of the philosophical issues and practical aspects involved in developing such a policy.
In developing countries, the problems of under-nutrition predominate. General agreement exists that the major cause is poverty and so the need to establish policies aimed at $c$ attacking the cause or treating the effects is unequivocally accepted by most nutritionists and planners, if not by $\overline{\mathrm{c}}$ politicians and decision makers. In developed countries, the situation is different. The major dietary-related health problems are those of over-nutrition such as obesity, coronary heart disease and dental caries. Some of the accumulating scientific evidence of the relationship of such diseases to specific dietary factors is conflicting. This is one reason for the lack of a food policy. Scientists and planners want unequivocal proof of cause and effect before committing the evidence as a basis for food and nutrition policy. The report discusses the philosophical concept of absolute proof and argues that more than enough evidence is already available for policy making. The idea of food planning is also resisted in the name of individual freedom but the report counters the argument by showing the extent to which food supply and consumption are already controlled by such means as agricultural subsidies and tariffs and by advertising. The anomalies are pointed out of a system in which there is on one hand a government-financed health service and on the other hand government policies that either promote or do nothing to discourage the high consumption of items generally considered detrimental to health at their present level of intake, e.g. subsidies on butter and control of price increases of sugar.

The report also reviews the means available at present, and improvements in them that could be made, to assess the level and distribution of food consumption in Britain, the main instrument being the annual National Food Survey.

Suggestions are made for increasing the usefulness of recommended dietary intakes for the purposes of planning $\mathbb{D}$ and of how food planning could be formulated and inteo grated within existing government policy making an administrative structures.

This report is not a comprehensive review but presents, in an original manner, many of the conflicts involved in promoting a national policy. A major omission is a study of the economic interests that would be threatened by policies to promote health. These would be a decisive factor balanced only by strong consumer pressure, a situation which does not exist to date.

Neuropsychology. A Textbook of Systems and Psychological Functions of the Human Brain

By Stuart J. Dimond. Pp. ix +560 , illustrated. Butterworths, London, Boston etc., 1980. $£ 25.00$.

This bold volume has defied the boundaries of conventional textbooks on neuropsychology both in the range of its topics and the extent of its theoretical framework. Whilst most researchers of cognitive skills are still pussyfooting across the cortex, Dr Dimond holds the entire brain in the palm of his hand. From this perspective he gives a confident description of the psychological functions of subcortical areas as well as cortical. Indeed, one of the most provocative themes of the book is that much, if not most, credit for intelligent behaviour can be given to subcortical structures. 'It is our belief that the cortex is the vast map of the brain where everything that the brain needs to draw upon is laid out in an orderly form, and that in reality it is the subcortical structures which do the job of selecting and assembling this information' (p. 62). This position is maintained when discussing individual cognitive skills such as visuo-spatial and language skills. A theory of this magnitude is premature to say the least.

Although the visionary nature of the ideas in this book may be seen as its weakness, the coverage of the literature is its strength. It draws widely on animal, experimental, 